\title{
Sikojen rehunmuuntosuhteen mittaus ja periytyvyys
}

\author{
Marja-Liisa Sevón-Aimonen 1), Soili Haltia 2) ja Jessica Coyne 3), \\ ${ }^{1)}$ MTT, Biotekniikka- ja elintarviketutkimus, Biometrinen genetiikka, 31600 Jokioinen \\ ${ }^{2)}$ Figen O, PL 40, 01301 Vantaa \\ ${ }^{3}$ Animal \& Bioscience Research Department, Animal \& Grassland Research and Innovation Centre, \\ Teagasc Moorepark, Fermoy, Co. Cork, Ireland.
}

\section{Tiivistelmä}

Rehukustannus on suurin yksittäinen kuluerä ja siksi se on sikojen jalostusvalinnassa taloudellisesti tärkeimpiä ominaisuuksia. Sioilla mittana käytetään yleensä rehunmuuntosuhdetta eli rehuyksikköä/elopainon kasvu kg (rehuyksikkö on 9.3 megajoulea nettoenergiaa). Sioilla rehunmuuntosuhteen mittaus rajoittuu yleensä lihasikoihin. Tilaoloissa saadaan vain kasvatuserä tai karsinakohtaisia rehunkulutustietoja, joten jalostusvalintaa varten rehunmuuntosuhteen mittaus toteutetaan koeasemalla. Rehunmuuntosuhteeseen vaikuttaa ennen kaikkea sian rasvoittuminen ja kasvunopeus, joiden periytymisaste on korkea tai ainakin kohtalainen. Siksi vakioidullakin ruokinnalla eläinten välillä on suuria eroja rehunmuuntosuhteessa. Myös niin sanotussa jäännösrehunkulutuksessa, eli rehunkulutuksessa, jossa on otettu huomioon kasvuun ja ylläpitoon kuluva energia, on vaihtelua. Käytännössä jäännösrehunkulutus on vielä vaikeampi mitata, koska siihen tarvitaan tieto eläimen kasvun koostumuksesta ainakin rasvan ja valkuaisen tarkkuudella. Tiloilla voidaan ruokintastrategialla vaikuttaa rehunmuuntosuhteeseen. Yleensä pyritään siihen, että sika kasvaa valkuaista geneettisen potentiaalinsa mukaisesti, mutta energian saantia rajoitetaan tarvittaessa kasvun loppuvaiheessa rasvan muodostumisen hillitsemiseksi. Tällöin päästään parhaaseen rehunmuuntosuhteeseen ja yleensä myös hyvään ruhon arvoon. Voimakas rajoitus hidastaa rasvan muodostumisen lisäksi myös valkuaisen kasvua ja lisää kasvuaikaa ja kokonaisrehunkulutusta. Energiaa kuluu myös elintoimintojen ylläpitoon, jolloin hitaalla kasvunopeudella ylläpitopäiviä tulee enemmän. Taloudellinen optimi on yleensä lievästi rajoitetulla ruokinnalla, mutta optimaaliseen rajoituksen voimakkuuteen vaikuttaa sika-aineksen geneettiset ominaisuudet, sukupuoli ja loppupainotavoite. Kun tarkastellaan rehunmuuntosuhteen geneettisiä tunnuslukuja, on tärkeää tietää, onko sikojen ruokinta ollut ruokahalun mukaista vai rajoitettua. Geneettisten korrelaatioiden ero eri ruokintastrategioilla riippuu myös ruokinnan rajoituksen voimakkuudesta ja sikaaineksen rasvoittumistaipumuksesta. Rehunmuuntosuhde on rajoitetulla ruokinnalla keskinkertaisesti ja geneettisesti suotuisasti korreloitunut lihaprosenttiin ja kasvunopeuteen ja myös lihakkuuden ja kasvunopeuden korrelaatio on suotuisa. Myös vapaalla ruokinnalla rehunmuuntosuhde on suotuisasti korreloitunut lihaprosenttiin mutta kasvun ja rehunmuuntosuhteen korrelaatio on nolla. Vapaalla ruokinnalla lihakkuuden ja kasvunopeuden välille muodostuu epäsuotuisa geneettinen korrelaatio. Monissa maissa, kuten myös Suomessa, rehunkulutusta mitataan koeasemaoloissa käyttäen yksilöllistä rehunkulutuksen seurantaa. Tässä tutkimuksessa tarkastellaan rehunmuuntosuhteen perinnöllisiä tunnuslukuja sekä koko lihasikajaksolta että erikseen kasvun eri vaiheissa. Aineistona käytetään Figen oy:n koeaseman ruokahalun mukaisesti ruokittujen sikojen yksilöllisiä rehunkulutus- ja kasvutietoja.

Asiasanat: kotieläinjalostus, sika, rehunmuuntosuhde, periytyvyys, korrelaatio 


\section{Johdanto}

Rehukustannus on suurin yksittäinen kuluerä ja siksi se on sikojen jalostusvalinnassa taloudellisesti tärkeimpiä ominaisuuksia. Suomessa sioilla mittana on käytetty yleensä rehunmuuntosuhdetta eli rehuyksikköä/elopainon kasvu kg ( rehuyksikkö on 9.3 megajoulea nettoenergiaa). Sioilla rehunmuuntosuhteen mittaus rajoittuu yleensä lihasikoihin. Koko tuotantoketjun rehunmuuntosuhde riippuu myös emakon ominaisuuksista kuten hedelmällisyys ja kestävyys. Tilaoloissa saadaan vain kasvatuserä- tai karsinakohtaisia rehunkulutustietoja, joten jalostusvalintaa varten rehunmuuntosuhteen mittaus toteutetaan koeasemalla. Rehunmuuntosuhteeseen vaikuttaa ennen kaikkea sian rasvoittuminen ja kasvunopeus, joiden periytymisaste on korkea tai ainakin kohtalainen. Siksi vakioidullakin ruokinnalla eläinten välillä on suuria eroja rehunmuuntosuhteessa kasvunopeudesta ja kasvun koostumuksesta riippuen. Rehunmuuntosuhteen parantaminen käy tiettyyn pisteeseen asti helposti näitä ominaisuuksia parantaen. Rehunmuuntosuhteen mittana voidaan käyttää myös jäännösrehunkulutusta, jolloin rehunkulutuksesta on vähennetty kasvuun ja ylläpitoon kuluva energia. On arvioitu, että jopa kolmannes rehunmuuntosuhteen vaihtelusta on jäännösrehunkulutuksen vaihtelua (Knap ja Wang, 2012). Käytännössä jäännösrehunkulutus on vielä vaikeampi mitata kuin rehunmuuntosuhde, koska siihen tarvitaan tieto eläimen kasvun koostumuksesta. Samaan lopputulokseen valintaa ajatellen voidaan päästä, kun jalostusarvostelut lasketaan monenominaisuuden mallilla ja ominaisuuksina käytetään rehunkulutusta yhdessä kasvunopeuden ja ruhonkoostumuksen kanssa (Knap ja Wang 2012).

Tiloilla voidaan ruokintastrategialla vaikuttaa rehunmuuntosuhteeseen. Yleensä pyritään siihen, että sika kasvaa valkuaista geneettisen potentiaalinsa mukaisesti, mutta energian saantia rajoitetaan tarvittaessa kasvun loppuvaiheessa rasvan muodostumisen hillitsemiseksi ja sitä kautta ruhon teuraslaadun parantamiseksi. Tällöin päästään parhaaseen rehunmuuntosuhteeseen ja yleensä myös hyvään ruhon taloudelliseen arvoon. Voimakas rajoitus hidastaa rasvan muodostumisen lisäksi myös valkuaisen kasvua ja lisää kasvuaikaa ja kokonaisrehunkulutusta. Taloudellinen optimi on yleensä lievästi rajoitetulla ruokinnalla, mutta optimaaliseen rajoituksen voimakkuuteen vaikuttaa sika-aineksen geneettiset ominaisuudet, sukupuoli ja loppupainotavoite. Loppupaino vaikuttaa voimakkaasti rehunmuuntosuhteeseen sillä rehun kulutus kasvua kohden kasvaa nopeasti sen jälkeen, kun sian kasvunopeus alkaa hidastua sen ohittaessa elopainoltaan n. 1/3 aikuispainosta ja samalla kasvun koostumus muuttuu enemmän rasvaa sisältäväksi. Rehunmuuntosuhteen muutos painon kasvaessa on otettava huomioon taloudellisesti optimaalista teuraspainoa laskettaessa.

Kun tarkastellaan rehunmuuntosuhteen geneettisiä tunnuslukuja, on tärkeää tietää, onko sikojen ruokinta ollut ruokahalun mukaista vai rajoitettua. Varsinkin geneettiset korrelaatiot kasvunopeuteen ja ruhon koostumukseen riippuvat ruokintastrategiasta ja sika-aineksen rasvoittumistaipumuksesta. Rehunmuuntosuhde on rajoitetulla ruokinnalla keskinkertaisesti ja geneettisesti suotuisasti korreloitunut lihaprosenttiin ja kasvunopeuteen ja myös lihakkuuden ja kasvunopeuden korrelaatio on suotuisa (Peltonen ja Sevon-Aimonen, 2009). Myös vapaalla ruokinnalla rehunmuuntosuhde on suotuisasti korreloitunut lihaprosenttiin mutta kasvun ja rehunmuuntosuhteen korrelaatio on nolla. Vapaalla ruokinnalla lihakkuuden ja kasvunopeuden välille muodostuu epäsuotuisa geneettinen korrelaatio (Peltonen ja Sevón-Aimonen, 2009). Monissa maissa, kuten myös Suomessa, rehunkulutusta mitataan koeasemaoloissa käyttäen yksilöllistä rehunkulutuksen seurantaa. Tässä tutkimuksessa tarkasteltiin rehunmuuntosuhteen perinnöllisiä tunnuslukuja sekä koko lihasikajaksolta että erikseen kasvun eri vaiheissa. Aineistona käytettiin Figen oy:n koeaseman ruokahalun mukaisesti ruokittujen sikojen yksilöllisiä rehunkulutus- ja kasvutietoja.

\section{Aineisto ja menetelmät}

Rehunmuuntosuhteen periytymisestä vapaalla ruokinnalla ja korrelaatioista muihin ominaisuuksiin on laskettu tunnusluvut vuonna 2009. Nyt tehtyyn uuteen tarkasteluun, jossa laskettiin rehunmuuntosuhteen ja keskimääräisen päiväkasvun periytymisasteet eri painoisilla sioilla ja näiden keskinäiset korrelaatiot, poimittiin Figen oy:n asemalla vuosina 2008-2010 kasvatetut yorkshirerotuiset koesiat, yhteensä 3976 eläintä. Lisäksi näille haettiin sukulaiseläimet, yhteensä 6351. Siat oli punnittu kokeen aikana n. 5 kertaa ja punnitukset keskittyivät kokeen alkuun ja loppuvaiheeseen. Punnitusjaksoille haettiin vastaavan ajan rehunkulutustiedot ja -koostumustiedot ja laskettiin rehunyksikköjenkulutus elopainon kasvu-kg:a kohti. Jokainen punnitusväli katsottiin oman a ominaisuutenaan eikä tässä vaiheessa periy- 
tymisastelaskennoissa sovitettu rehunmuuntosuhdetta kuvaamaan mitään käyrää. Rehunmuuntosuhteet jaettiin punnitusvälin keskiarvopainon mukaan $20 \mathrm{~kg}$ välein. Kasvatusjakson alun punnitukset oli tehty lähekkäin n. kolmen päivän välein ja kasvatusjakson loppuvaiheen punnitukset n. 17 pv välein. Keskivaiheella kasvatusjaksoa punnituksia oli vähän joten ne jätettiin pois analyyseistä, eli tarkastelu painottuu alku- ja loppukasvatukseen. Aineisto analysoitiin monenominaisuuden eläinmallilla käyttäen REML-menetelmää ja DMU-ohjelmistoa. Tutkittavina ominaisuuksina olivat punnitusvälien rehunmuuntosuhteet ja keskimääräiset päiväkasvut . Periytymisasteiden laskentaa varten varianssit otettiin yhden ominaisuuden mallista ja korrelaatiot kahdenominaisuuden mallista. Selittävinä muuttujina olivat sukupuoli, kasvatuserä ja satunnaisena pysyvänä ympäristötekijänä pahnue ja satunnaisena additiivisena perinnöllisenä tekijänä eläin. Satunnaistekijät eli pahnue-, eläin- ja jäännöstekijä oletettiin toisistaan riippumattomiksi ja normaalisti jakautuneiksi.

\section{Tulokset ja tulosten tarkastelu}

Tarkastellulla kasvatusjaksolla rehunmuuntosuhteessa näkyi eksponentiaalinen muutos keskimääräisen päiväkasvun muuttuessa lineaarisesti elopainon kasvaessa (kuvio 1). Teoriassa rehunmuuntosuhde heikkenee eli rehua alkaa kulua kasvua kohti enemmän kun päiväkasvu hidastuu ja ylläpitorehun osuus syödystä rehusta kasvaa. Lisäksi kasvun koostumus siirtyy lihaksista enemmän energiaa sisältävän rasvakudoksen kasvuun.

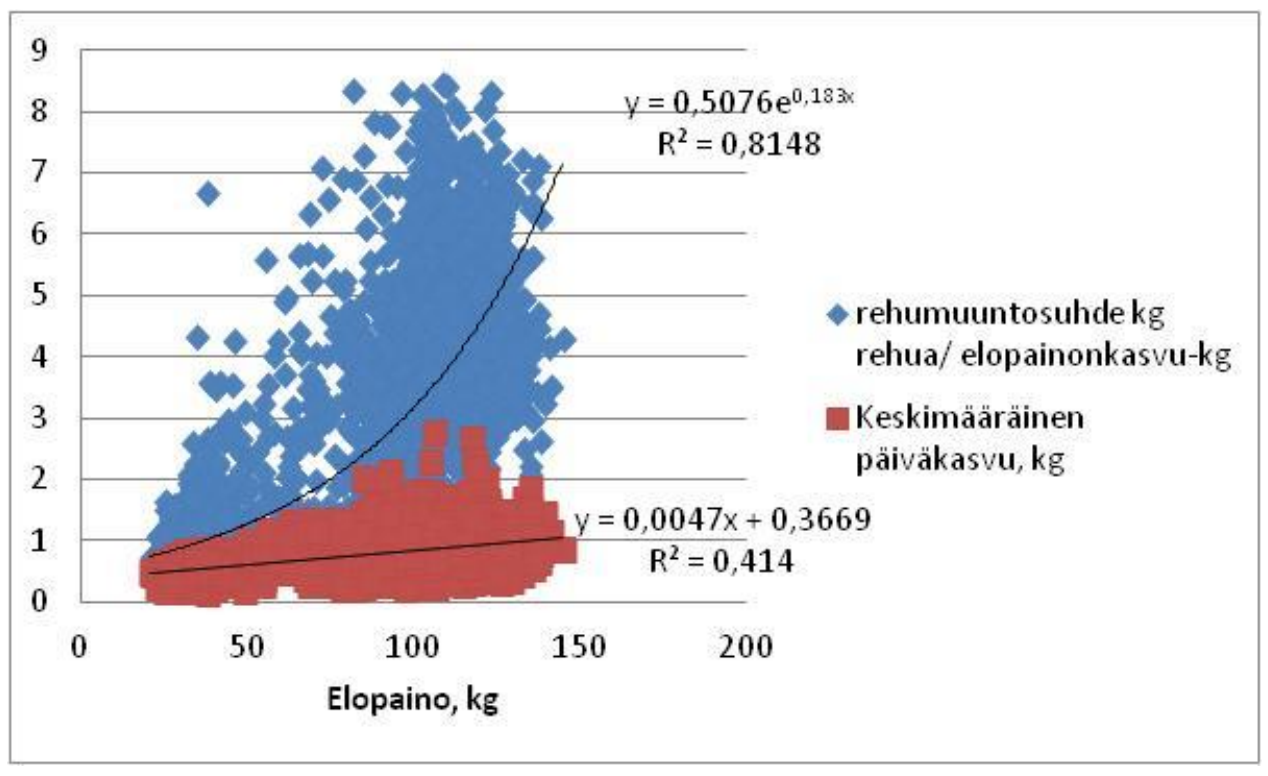

Kuvio 1. Rehunmuuntosuhteen ja keskimääräisen päiväkasvun kehitys yorkshirerotuisten koesikojen elopainon noustessa

Periytymisasteet, geneettiset korrelaatiot ja estimaattien keskivirheet eri painoväleillä on esitetty taulukossa 1. Rehunmuuntosuhteen periytymisasteet vaihtelivat 0,02 ja 0,20 välillä, mutta johtuen suurista keskivirheistä vain ensimmäisen painovälin periytymisaste oli merkitsevä. Vastaavat kasvun periytymisasteet vaihtelivat 0,12 ja 0,32 välillä ja olivat alinta painoväliä lukuun ottamatta merkitseviä. Aiemmin estimoidut periytymisasteet koko kasvatusjakson rehumuuntosuhteelle samalla rodulla ja koeasemalla olivat 0,30 ja kasvunopeudelle 0,31 (Peltonen ja Sevón-Aimonen, 2009).

Eri painovälien rehunmuuntosuhteen ja keskimääräisen päiväkasvun korrelaatio oli negatiivinen, eli nopeakasvuisemmat kuluttivat vähemmän rehua elopainon kasvua kohti. Alimmissa kahdessa painovälissä korrelaatio oli -0,32 ja -0,33 (ei merkitseviä) ja ylimmissä -0,73 ja -0,66 (merkitseviä). 
Taulukko 1. Yorkshirerotuisten koesikojen eri painoväleille laskettujen rehunmuuntosuhteen ja keskimääräisen paiväkasvun periytymisasteet $(\mathrm{h} 2)$ sekä näiden väliset geneettiset korrelaatiot $\left(\mathrm{r}_{\mathrm{g}}\right)$ keskivirheineen (SE)

\begin{tabular}{|lrrrrrrr|}
\hline \multicolumn{7}{c|}{ Rehunmuuntosuhde } & \multicolumn{7}{c|}{ Keskimääräinen päiväkasvu } \\
\hline Painoväli & $\mathrm{N}$ & $\mathrm{h}^{2}$ & $\mathrm{SE}$ & $\mathrm{h}^{2}$ & $\mathrm{SE}$ & $\mathrm{r}_{\mathrm{g}}$ & $\mathrm{SE}$ \\
\hline$<30 \mathrm{~kg}$ & 377 & 0.20 & 0.19 & 0.12 & 0.16 & -0.32 & 0.73 \\
\hline $30 \mathrm{~kg}-49.9 \mathrm{~kg}$ & 1501 & 0.02 & 0.04 & 0.32 & 0.09 & -0.33 & 0.38 \\
\hline $90 \mathrm{~kg}-109.9 \mathrm{~kg}$ & 1035 & 0.04 & 0.05 & 0.12 & 0.07 & -0.73 & 0.35 \\
\hline $110 \mathrm{~kg}-129.9 \mathrm{~kg}$ & 750 & 0.08 & 0.09 & 0.29 & 0.12 & -0.66 & 0.31 \\
\hline
\end{tabular}

\section{Johtopäätökset}

Rehunkulutuksen yksilöllinen seuranta mahdollistaa myös yksilöllisen rehunmuuntosuhteen laskennan sioille, mikä tehostaa rehunmuuntosuhteen valintaa. Ruhon koostumuksen muutos vähärasvaisemmaksi ja parantunut kasvunopeus ovat osaltaan parantanut rehunmuutosuhdetta. Kuitenkin arviolta kolmannes rehunmuuntosuhteen vaihtelusta on jäännösrehunkulutuksessa. Rehunmuuntosuhteen muutoksen tunteminen kasvatusjakson aikana auttaa tekemään poistopäätöksiä taloudellisesti optimaalisesti. Rehunmuuntosuhteen kehitystä kuvasi parhaiten eksponentiaalikäyrä. Tässä tarkastelussa kasvatusajan punnitusten vähyys ja painon suhteen epätasainen jakautuminen vähensivät mahdollisuutta vertailla periytymisasteen muutoksia kasvatuskauden kuluessa. Jos mittaus tehtäisiin käsiruokinnalla, parhaiten periytyvän jakson tunnistaminen voisi auttaa kohdentamalla mittaukset tähän, mutta automaattiruokinnalla koko kasvatusjakson kulutuksen seuranta on järkevintä. Koska rehunmuuntosuhde ja kasvunopeus muuttuvat eläimen painosta ja kasvuvaiheesta johtuen, tämä pitäisi ottaa huomioon näiden ominaisuuksien jalostusarvojen laskennassa.

\section{Kirjallisuus:}

Knap, P.W.\& Wang, L. 2012. Pig breeding for improved feed efficiency. Teoksessa: John F. Patience (toim.). Feed efficiency in swine. Wageningen Academic Publisher.275 s.

Peltonen, A. \& Sevón-Aimonen, M.-L. 2009. Genetic parameters for meat percentage, average daily gain and feed conversion rate in Finnish landrace and Large White pigs. In: Book of abstracts of the 60th annual meeting of the European Association for Animal Production, Barcelona, Spain 24-27 August 2009. EAAP Book of abstracts 15 15: s. 433. 